\title{
Feedback in Teacher Education: Interns' Perceptions
}

\author{
Archana Kushwaha \\ Department of Elementary Education, University of Delhi, India
}

\begin{abstract}
Field experience is one of the most influential components in preparation of pre-service teachers in a teacher education programme. College supervisors have an important responsibility of supporting and guiding interns during this period. For supervisors' feedback to be effective in leading to change in interns' classroom practice, it should be well received by the teachers at whom it is directed. This study was an attempt to understand how interns felt about the feedback they received from their college supervisors during their internship in school and identify those aspects of the feedback which helped them become reflective teachers. The study brings to light several aspects of supervision including those that helped them improve classroom practices as well as others which invited disapproval or were considered unproductive.
\end{abstract}

Keywords: feedback, field experience, internship, interns' perceptions, reflective teaching, supervision

\section{Introduction}

There are two key participants in the practice teaching component of the Bachelor of Elementary Education Programme in the University of Delhi- college supervisors and the student teachers. Supervisors have the responsibility of providing support and guided assistance to interns in preparing lesson plans, establish linkages of theory with practice, evaluate the teaching performance of a student teacher during the internship and most importantly, lead them towards growth and foster reflective thinking. To be able to fulfil these multifarious responsibilities, it is important for her to be aware of how her feedback is received by student teachers. This paper looks at the comments of student-teachers regarding the problems and challenges they face during their internship and their perception of the feedback received by their supervisors. It also aims to get their perspective on the kind of feedback they found most useful in shaping the quality of their teaching practice and making them more reflective.

\subsection{Importance of Field Experience}

The experience of teaching in a school is often considered one of the most influential factors in the preparation of pre-service teachers in a teacher education programme. [1]Tang (2003) suggests that field experience is at the heart of the student teachers' professional training. [2]Richardson (1996) argues that school experience shapes beginning teachers' constructions of teaching, learning and the contexts in which these take place. [3]Caires and Almeida (2005) see teaching practice as responsible for a 'personal revolution' in students' knowledge of themselves as teachers, knowledge of management of teaching/learning process, of school cultures and of the education system itself.

Although research points to the many benefits of practice teaching component of teacher preparation, the positive elements of this experience cannot be assumed. [4]Dewey (1938) reminds us that all experiences cannot be considered genuinely educative as experience and education cannot be directly equated. Even [5]Zeichner (1996) has cautioned that field experience is so important that it should not be left to chance. Given that learning to teach is not only a complex process but also, very often, a highly emotional and challenging one, it is necessary to examine the difficulties faced by many students in achieving a positive early experience of teaching.

\subsection{Field Experience in the B.El.Ed programme}

B.El.Ed is a four years teacher education course which places special emphasis on field experience in its curriculum. Students are exposed to actual classrooms in the first year when they go for school contact programme for 10 days. During this time they organize interesting and innovative activities in the classroom. In third year students observe classrooms and teach in pairs for a period of two weeks. Students undergo an extended sixteen week internship programme in fourth year which requires them to get attached to a school ( usually a Municipal Corporation of Delhi School) and work as almost full time teachers. Students prepare subject-wise Unit Plans and lesson plans and discuss them with their subject supervisors before it is transacted in the class. Students maintain reflective journals in which they write about their experiences with respect to classroom teaching, their success and failures, choice of materials/activities and their appropriateness and other issues such as time management, discipline and so on. 


\subsection{Importance of Feedback in Practice Teaching}

As mentioned earlier, a supervisor has the responsibility of leading students toward professional growth and making them more reflective. Her engagement with student teachers through discussions, dialogues and feedback during internship constitutes an important factor in determining how they look at the experience of teaching. Giving and receiving feedback are essential activities in practice teaching. Giving feedback to interns requires a complex interplay of communication, analytical and interpersonal skills [6](Gibson 2006). The general literature on feedback reveals that quality feedback, whether spoken or written, helps learners confirm the intended outcome of the learning/ situation, motivates them to continue and move on, enables them to assess their learning/performance, and lets them identify the next step. [7]Vasquez and Reppen(2007) argue that effective feedback allows for dialogue between student and teacher of a kind that promotes thinking and reflection and evokes and explores understanding. The dialogue must be such that learners have an opportunity to think and express their ideas.

Feedback should facilitate reflection and foster critical thinking skills of student teachers on their own teaching skills. Reflection was introduced as a goal in teacher education in the early 1980's, especially as a result of the work of [8]Schon $(1983,1987)$. Reflection is seen as a way to enhance teacher autonomy by encouraging them to examine the beliefs and thinking patterns which underlie their classroom actions [9](Richards and Lockhart 1996). Many teacher education programs stress processes that foster reflective capabilities of observation, analysis, interpretation and decision making [10](Zeichner \& Liston 1987). If reflection is a desired goal then the supervision of practice teaching should also be geared at helping students become reflective teachers. Since giving and receiving feedback are essential activities and crucial to development of successful teachers and improving the standard it is necessary to explore student teachers' perception of the feedback given to them and identify the features that actually create positive effects in terms of enabling them to become more reflective.

\section{The Study}

This study examined the interns' perception of the feedback they received from their college supervisors about their lesson plans and classroom teaching. This was done through interviews which were conducted during their three and half month long primary school internship. The questions that guided the interview during the internship were:

a) What was their perception of the feedback they received from supervisors?

b) Has it influenced their teaching practice and how?

Data was collected from fourteen interns who were attached to a Municipal Corporation of Delhi (MCD) school for their internship. The interns are fourth year students of the Bachelor of Elementary Education course of the University of Delhi. Since the investigator is herself one of the supervisors, her position could have influenced interns' responses. To minimize this, they were oriented about the purpose of interview prior to it. They were told that the confidentiality and privacy of participants will be protected and that it would not affect the evaluation of their performance in any manner. They were asked not to take any names while talking about the feedback practices of their supervisors. The interviews were recorded and were later analyzed qualitatively.

\section{Findings}

An intern's workload in school includes doing most of the activities that a regular teacher at the school is expected to do, that is, conduct morning assembly, correct notebooks, do up the classroom bulletin board, supervise distribution of mid-day meal, organize classroom as well as school level competitions and other events and so on. This is over and above the regular teaching of the four school subjects - English, Hindi, Mathematics and Environmental Studies. Completing the syllabus and preparing students for exams is a part of their teaching work.

Questions of the interview were designed to identify interns' perception of the feedback they received from their supervisors with regard to their lesson planning and its transaction in classroom. It also aimed to find out if they found this feedback useful in improving their practice and in what ways.

In the interview, interns expressed satisfaction with some aspects of feedback given to them. For example one intern shared how from initially disagreeing with her supervisors' suggestions she, over a period of time, was able to understand and appreciate her viewpoint and was able to bridge the gap between theory and practice. Supervisors also supported interns in their growth as a teacher and adjustment in the school setting.

$>$ My supervisor asked me to use concrete materials such as beads, stones, leaves etc in my class. Initially it led to a lot of chaos. I told her it wasn't working, but she insisted that I do it. So I kept trying and realized that with time students got used to handling materials. My students now listen to my instructions. They know what I expect them to do with these materials. There is lesser noise also. Now, I think it was a good suggestion to use concrete materials. 
$>$ My supervisor helped me settle down in my teaching zone. She helped me adjust and become a better teacher. She dealt with each one of us in a different way.

Interns appreciated the compliments and praise given to them by some of the supervisors. Their comments were encouraging and helped them feel more confident about themselves.

$>$ I like the way she gives feedback. She begins by pointing out my strengths and good things about my class. Then she goes on to problem areas...

$>$ She gives specific examples on how to do better.

$>$ She gives suggestions but doesn't thrust her perspective on us.

$>$ My supervisor's written feedbacks were like she was talking to me. She forms a connect with us...

Interns' comments revealed that they like feedback which enables them to identify their strengths and weaknesses. A feedback which is a presented in form of possible alternative rather than a directive to improve their teaching is appreciated and received in a positive way. They appreciate comments that are detailed and specific in nature rather generalized statements. However, they did not say this for all the supervisors.

$>$ My supervisor wants the lesson to be delivered her way. She doesn't listen to me and doesn't understand my point of view. It seems my opinion has no value. So I have become manipulative...

$>$ I work according to the expectations of my supervisor.

$>$ Supervisors' comments can be very discouraging. Sometimes the language used is harsh...

$>$ One of my supervisor wrote her feedback as if she was addressing a student she doesn't know... like... she is an external examiner who doesn't know me. I would rather have a feedback which has a personal touch.

It is evident from these comments that the supervisor's speech act also determines the way a feedback is received. They expect a balance of praise and criticism in feedback. They disapprove of supervisors who do not give space to inters' point of views or allow disagreement or questioning in their discussion. The language used by supervisors in their feedback also emerges as an important determinant of how students receive feedback. Feedback or suggestions which is delivered authoritatively or using stern language is neither appreciated nor incorporated.

There were some comments that point towards dissatisfaction with supervisors' feedback. Interns do not always accept the advice given to them though they may not express it for various reasons. They felt that supervisors make judgements based to their observation of a class which does not last for more than 20-25 minutes. Also, while the regular supervisor visits once every week, the subject supervisor comes for supervisory visits only once in fortnight. The frequency of their visits as well as the duration of observation was not enough to make any fair assessment of their practice.

It is clear that interns expect their supervisors to understand their experiences, limitations of a given school situation and be sensitive to the difficulties they may be facing and. All this may not be possible during the short period of supervisory observation. Since the assessment of an interns' performance is based on limited number of visits, some of them have developed an understanding that they have to be their "best" while the supervisor is observing their class:

$>$ I save my best activity for the supervision day. If needed, I repeat it because I know it's good.

$>$ There are some activities I keep aside for supervision day. I make it a point to use some teaching learning material on that day even if I know I can teach better without it.

These interns have interpreted teaching as a set of expectations by their supervisors. They prepare especially for the "supervision day" in order to impress the supervisor. It is interesting to note that there are many interns who can see a problem in such system and refuse to compromise their students' learning in order to impress their supervisor. In both cases there is a clear dissatisfaction and anger with the whole concept of assessment based on observation. Interns find observation model of supervision as both inadequate and problematic. They wanted observation to be either regular so that the supervisor could get a holistic understanding of the interns' effort at developing the concept which does not happen on a particular day or moment but an exercise which is continuous. Their comments also hint at supervisors' inability to establish a relationship with their interns, a relationship which is characterized by willingness to understand their perspective and responding to the pedagogical and emotional needs of the interns.

Interns' comments reflected dissatisfaction with the assessment. They raise an important issue of assessment based on observable performance. Is observable performance an adequate evidence of students' progress? [11]Delandshere and Arens (2001) caution that 'shift to performance has the potential to focus on most visible aspects of teaching but not necessarily on most important ones'. Such an assessment seems to limit diversity of both action and thought, constrain creativity and individuality rather than support professional 
development. Interns have interpreted teaching in front supervisors as a display of evidence of good teaching rather than teaching itself. They also doubt whether it is possible to give adequate evidence for all aspects of teaching. Displaying an evidence of teaching has become an end in itself. For some interns it is an overbearing concern which hinders them from achieving their complete potential as teachers.

Interns' comments regarding the nature of feedback given to them had considerable diversity. There were some students who wanted feedback to be more specific:

$>$ I did not get any feedback on my pedagogy. She only said that my lesson plan needs to be more interesting.

$>$ Suggestions should be proper and clear. It would be good if I know what exactly she expects me to do.

It is interesting to note that the above set of comments contradicts the comments made by another group of students which did not want directive feedback. They wanted the feedback to be more flexible; one which allows them to try out their own ideas, experiment and help them arrive at their own conclusions. They did not want their supervisors to impose their ideas on them.

\section{Discussion on Findings}

The purpose of this study was to examine interns' perception of the feedback received by their supervisors during internship. It also aimed at identifying those aspects of feedback which helped them improve their practice and become reflective teachers. During the interview sessions interns raise several issues related to assessment, purpose, duration and frequency of supervision, language used by supervisors and so on. The study brings to light several aspects of supervision including those that helped them improve classroom practices as well as others which invited disapproval or were considered unproductive. The specific findings of this study are discussed below:

The study clearly suggests that interns' perceive supervisors' feedback to be a major factor in shaping their experience of becoming a teacher. They have a tendency to measure their success and failures in field in terms of how positive or negative the feedback on their teaching was. No doubt, they expected feedback to be a balance of compliments and criticism. This, they felt was necessary to keep them motivated as well as confident about their abilities.

Interns felt that some of their supervisors helped them form linkages with theory and practice. They were instrumental in helping them explore their potential, grow as professionals and adjust well in the school setting. These supervisors provided feedback related to their teaching, helped them deal with specific problems such as pupil behaviour, time and workload management. Most importantly, they gave them confidence through constant recognition, encouragement and trust. They appreciated supervisors who treated them as individuals with their unique emotional and professional needs.

There was a lot of diversity in interns' perception of nature of feedback they found useful. Their responses ranged from expecting supervisor to tell them what should be done and giving them clear and detailed instructions to improve to interns who needed feedback which would help them identify and explore their strength and weaknesses and develop their own theories. These interns would respond favourably to a feedback which was presented as a possibility rather than a directive to improve their teaching and lesson planning.

Supervisors' language while delivering compliments, criticisms and suggestions emerged as an important factor in determining how a feedback was received by interns. Supervisors needed to be particularly sensitive while delivering critical feedback. Authoritative tone or stern language while delivering oral or written feedback gives rise to misgivings among interns.

All the Interns raised the issue of assessment based on observed classes. They found the frequency and duration of observation visits inadequate. They felt assessment should be continuous and holistic. By holistic, they meant all aspects of the teaching learning situation should be taken into account before assessing.

Interns wanted assessment to be regular because they felt that the supervisors could understand their pedagogy better if they could see the how they develop a concept over a period of time, see a linkage between the various activities and how and why they follow a certain pedagogical practice in their classroom. In the absence of this, a supervisor may find teaching disjointed, abrupt and fragmented. The interns' comments seemed to indicate that assessment based on observation leads to adoption behaviours which helps intern avoid negative assessments. They show their 'best' in front of the supervisor. Some of them think that teaching is about meeting the expectations of the supervisors.

Inspite of their best intentions, not all of supervisors' feedback is favourably viewed by the interns. Since internship is a period of numerous pressures and challenges, there is a need for constant dialogue, interaction and openness between a supervisor and intern. In the absence of this, interns develop a tendency of disagreeing with and complaining about supervisors. 


\section{Conclusion}

The findings in this study brings to fore features of supervision that were received favourably as well as those which were at best ineffective and at worst counterproductive. Some of the aspects of feedback which were effective in enabling interns to improve practice and foster reflective abilities were delivery of compliments, praise, encouragement, specific suggestions with regard to teaching performance, a balance of both positive and negative comments delivered in a personalized way, presentation of suggestion as alternative ways rather than 'should/must do' statements. Interns have raised issues related to observation based assessment, understanding limitations of the school setting, language of feedback and possibility of involving school teachers in the assessment process.

To sum up, the findings of this study could inform the supervisors' about feedback practices that are likely to be well received by interns. This is especially needed since their positive perceptions regarding feedback could serve an important step in enabling them to act on it and better their teaching. The study also confirms the importance of relational and situated aspects of supervision. Supervisors' communication skills and ability to form relationship of trust can go a long way in making their feedback more constructive and accepted by interns. However, the study relied only on interns' comments on feedback given to them and does not examine supervisors' use of different strategies in giving feedback and their perspective on its effect on interns. Further studies may be necessary to confirm these findings.

\section{References}

[1] Tang S (2003), Challenge and support: The dynamics of student teachers' professional learning in the field experience, Teaching and Teacher Education 19: 483-98

[2] Richardson V (1996) The role of attitudes and beliefs in learning to teach. In Handbook of Reasearch in Teacher Education, ed. J Sikula, 102-19, New York: Simon and Schuster Macmillan

[3] Caires S and Almeida L (2007), Positive aspects of teacher training supervision: The student teachers' perspective, European Journal of Psychology of Education, 22(4), 515-528

[4] Dewey J (1938) Education and experience, New York: Simon and Schuster

[5] Zeichner K (1996) Designing educative practicum experiences In Currents of Reform in preservice teacher education, ed. K. Zeichner, S Melnick and M L Gomez, 215-34, New York and London: Teachers College, Columbia Univ.

[6] Schon D (1983) The reflective practitioner: How professionals think in action, New York: Basic Books

[7] Gibson S A (2006), Lesson observation and Feedback: The practice of an expert reading coach, Reading Research and Instruction, 45, no. 4: 295-308

[8] Vasquez C and R Reppen (2007) Transforming practice: Changing patterns of participation in post-observation meeting. Language Awareness 16 no. 3: 153-72

[9] Richards J C and C Lockhart (1996) Reflective Teaching in second language classrooms, Cambridge: Cambridge Univ. Press

[10] Zeichner K M and Liston D P (1987) Teaching student teacher to reflect, Harvard Educational Review, 57, 23-48

[11] Delandshere G and S A Arens (2001) Representations of teaching and standards-based reform: Are we closing the debate about teacher education? Teaching and Teacher Education, 17. no 5: 547-6 